\title{
Diagnostic Accuracy of Carba NP test for Rapid Detection of Carbapenemase-Producing Enterobacteriaceae: Systematic Review and Meta-Analysis
}

\author{
Zean Zefenkey ${ }^{1}$, Salah M. Saleem², Nyan J. Mohammed ${ }^{3}$ \\ ${ }^{1}$ Lecturer, ${ }^{2}$ Professor, ${ }^{3}$ Assistant Lecturer, Department of Medical Laboratory Sciences, College of Sciences, \\ Knowledge University, Erbil, Kurdistan Region, Iraq
}

\begin{abstract}
Background: Carbapenem-Resistant Enterobacteriaceae is a major health concern that needs a fast response by rapid detection and management. The Polymerase chain reaction is the gold standard method for the detection of this infection, but it is expensive and needs special laboratory facilities, so there is an urgent demand for an alternative method characterized by cheap, rapid, and accurate. CARPA NP test has been proposed as a rapid method for the detection of Carbapenemase-Producing Enterobacteriaceae, but its overall accuracy has not been systematically estimated. We performed a systematic review and meta-analysis to evaluate the accuracy of CARPA NP test for the detection of Carbapenemase-Producing Enterobacteriaceae.
\end{abstract}

Methods: We searched Pubmed and Embase databases and eighteen studies met our inclusion criteria. We utilized summary receiver operating characteristic (SROC) to summarize the accuracy. Results: The sensitivity and specificity of CARPA NP test were 0.96 (95\% CI, 0.92 to 0.98$)$ and 1.00 (95\% CI, 0.97 to 1.00 ) respectively, the positive likelihood ratio was 33.1 (95\% CI, 24.3 to 45.1$)$, the negative likelihood ratio was 0.06 (95\% CI, 0.05 to 0.07), and the diagnostic odds ratio was 573.46 (95\% CI, 397.4 to 827.49).

Conclusion: CARPA NP test has a high level of accuracy for the rapid detection of CarbapenemaseProducing Enterobacteriaceae. Additional studies are required to estimate the accuracy of Carba NP test when applied directly to clinical samples, especially in areas with high rates of carbapenemase-producing Enterobacteriaceae

Keywords: Carbapenemase-Producing Enterobacteriaceae; Carbapenem-Resistant Enterobacteriaceae; Carba NP test; Diagnostic Accuracy.

\section{Introduction}

Carbapenemase-Producing Enterobacteriaceae (CPE) is a major worldwide health concern, as this term referring to strains of Enterobacteriaceae that produce transmissible carbapenemase, making theses strains resistant to all $\beta$-lactams antibiotics (all antibiotics sometimes), which leads to a very difficult treatment

\section{Corresponding author:}

Zean Zefenkey

e-mail: zean.zefenkey@knu.edu.iq and an increase in mortality ${ }^{1}$. The mortality of carbapenemase-producing Klebsiella pneumonia, as for instance, is about $41 \%^{2}$.

Since 2013, The Centers for Disease Control and Prevention (CDC) reported Carbapenem-resistant Enterobacteriaceae as the most serious category of antibiotic resistance threats - urgent threat - which requires fast and effective response ${ }^{3-4}$.

Carbapenemase enzyme includes many classes A, $\mathrm{B}$, and D based on the molecular structure. Class A and 
$\mathrm{D}$ carbapenemase have a hydrolytic mechanism depends on serine, whereas class B carbapenemase contains zinc in its active site ${ }^{5}$.

There are many mobile genetic elements such as plasmids that carry carbapenemase genes and transmit them quickly between gram-negative bacteria, so the fast detection of all gram-negative carbapenemase producers is very important to prevent this transmission and its consequences 6,7. This fact makes the identification of rapid, easy, and cheap method for the detection of carbapenemase-producing bacteria has been an urgent demand for microbiologists.

Carba NP test is a biochemical method were suggested to tackle this challenge ${ }^{8}$, this test depends on the direct detection of Carbapenemase-producing bacteria by Carbapenem hydrolysis, it is applied successfully for Enterobacteriaceae ${ }^{9-11}$, Pseudomonas aeruginosa and Acinetobacter baumannii ${ }^{12-15}$. Carba NP test can detect all classes of carbapenemase (without distinction) in less than two hours, making it a rapid test for the detection of $\mathrm{CPE}{ }^{8}$.

As a number of studies have evaluated the diagnostic accuracy of CARBA NP for detecting CarbapenemaseProducing bacteria, we conducted a systematic review and meta-analysis to evaluate the overall accuracy of this assay and to investigate whether CARBA NP test is sufficiently specific and sensitive in order to enable early detection of CPE.

\section{Methods}

\section{Search strategy}

Pubmed and Embase databases were the main sources for a search of articles and abstracts. The search was done from inception to 18 June 2020, using the keywords: "carbapenemase-producing", "Enterobacteriaceae" "rapid test", " $\beta$-lactamases", "carbapenemase-resistant", "Carba NP test", “ diagnostic accuracy “, "sensitivity”, and "specificity". The references of all articles and abstracts were searched for more studies.

\section{Studies selection}

We documented results from all studies that evaluate the diagnostic accuracy (sensitivity and specificity) of the Carba NP test for the detection of CPE in both clinical specimens and bacterial isolates.

We determined the following criteria to include the study in this systematic review and meta-analysis: 1- studies that compared the Carba NP test with PCR; 2studies that reported on the detection of CarbapenemaseProducing Enterobacteriaceae; 3- and studies that reported data separately for carbapenemase-producing and non-producing isolates.

Moreover, all articles which are not available in English were excluded from this study.

\section{Data extraction and assessment of quality}

All articles were screened by two reviewers independently to confirm that they match the criteria of this study and any discrepancies were handled by team discussion. The data of each study were extracted into a $2 \mathrm{X} 2$ table to calculate the results of the diagnostic accuracy of Carba NP test. The information of the studies were classified to the following parameters: author, year of publication, the specimen type, the sample size, and the number of (true positive, false positive, true negative, and false negative samples)

The risk of bias of the included studies were presented by assessment of the quality of studies by using the Quality Assessment of Diagnostic-Accuracy Studies (QUADAS) 2 tool ${ }^{16}$.

\section{Data synthesis and statistical analysis}

All articles were screened by two reviewers independently to confirm that they match the criteria of this study and any discrepancies were handled by team discussion. The data of each study were extracted into a $2 \mathrm{X} 2$ table to calculate the results of the diagnostic accuracy of Carba NP test. The information of the studies were classified to the following parameters: author, year of publication, the specimen type, the sample size, and the number of (true positive, false positive, true negative, and false negative samples) 
The risk of bias of the included studies were presented by assessment of the quality of studies by using the Quality Assessment of Diagnostic-Accuracy Studies (QUADAS) 2 tool ${ }^{16}$.

\section{Results}

Our primary searches identified 1405 articles, and from these studies, eighteen articles ${ }^{8-11,19-32}$ met eligibility criteria and are accepted in this study. The main reasons for exclusion are : did not include original data, a reference test other than PCR was used, and the study was not reported in English.

The most common reasons for exclusion were that the reference test other than PCR was used, the study did not review full data, or the study was not published in the English language.

(Table 1) presents the main characteristics and results of the 18 included studies.

TABLE 1 Characteristics of 18 individual studies included in the systematic review

\begin{tabular}{|c|c|c|c|c|c|c|}
\hline $\begin{array}{c}\text { Authors, publication yr } \\
\text { [reference] }\end{array}$ & Specimen type & $\begin{array}{c}\text { Total no of } \\
\text { specimens } \\
\text { (carpa+/carpa-)a }\end{array}$ & $\mathrm{TPb}$ & FPc & $\mathrm{TNd}$ & $\mathrm{FNe}$ \\
\hline Bayraktar et al, 201931 & $\begin{array}{l}\text { Bacterial } \\
\text { isolate }\end{array}$ & $110 / 15$ & 109 & 0 & 15 & 1 \\
\hline Bayramoğlu et al, 201630 & $\begin{array}{l}\text { Bacterial } \\
\text { isolate }\end{array}$ & $65 / 78$ & 61 & 0 & 78 & 4 \\
\hline Bernabeu et al, 201724 & $\begin{array}{l}\text { Bacterial } \\
\text { isolate }\end{array}$ & $121 / 55$ & 117 & 0 & 5 & 4 \\
\hline Bir et al, 201910 & $\begin{array}{l}\text { Bacterial } \\
\text { isolate }\end{array}$ & $33 / 7$ & 31 & 2 & 5 & 2 \\
\hline Bogaerts et al, 201621 & $\begin{array}{l}\text { Bacterial } \\
\text { isolate }\end{array}$ & $178 / 146$ & 158 & 0 & 146 & 20 \\
\hline Dortet et al, 2001422 & blood culture & 193/74 & 189 & 0 & 74 & 4 \\
\hline Dortet et al, 201511 & $\begin{array}{l}\text { Bacterial } \\
\text { isolate }\end{array}$ & $95 / 55$ & 92 & 0 & 55 & 3 \\
\hline García-Fernández et al, 201628 & $\begin{array}{l}\text { Bacterial } \\
\text { isolate }\end{array}$ & $159 / 70$ & 159 & 0 & 70 & 0 \\
\hline Gauthier et al, 201723 & $\begin{array}{l}\text { Bacterial } \\
\text { isolate }\end{array}$ & $163 / 93$ & 158 & 0 & 93 & 5 \\
\hline Huang et al, 201419 & $\begin{array}{l}\text { Bacterial } \\
\text { isolate }\end{array}$ & $72 / 63$ & 69 & 0 & 63 & 3 \\
\hline Lifshitz et al, 201626 & $\begin{array}{l}\text { Bacterial } \\
\text { isolate }\end{array}$ & $69 / 29$ & 56 & 4 & 29 & 13 \\
\hline Literacka et al, 201727 & $\begin{array}{l}\text { Bacterial } \\
\text { isolate }\end{array}$ & $451 / 464$ & 432 & 31 & 433 & 19 \\
\hline Muntean et al, 201825 & $\begin{array}{l}\text { Bacterial } \\
\text { isolate }\end{array}$ & $85 / 28$ & 79 & 0 & 28 & 6 \\
\hline Nordmann et al, 20128 & $\begin{array}{l}\text { Bacterial } \\
\text { isolate }\end{array}$ & $162 / 46$ & 162 & 0 & 46 & 0 \\
\hline
\end{tabular}


Cont... TABLE 1 Characteristics of 18 individual studies included in the systematic review

\begin{tabular}{|c|c|c|c|c|c|c|}
\hline Pancotto et al, 2018 9 & $\begin{array}{c}\text { Bacterial } \\
\text { isolate }\end{array}$ & $43 / 40$ & 27 & 39 & 16 & 32 \\
\hline Pires et al, 201629 & $\begin{array}{c}\text { Bacterial } \\
\text { isolate }\end{array}$ & $30 / 33$ & 30 & 1 & 0 & 69 \\
\hline Tamma et al, 2017 32 & $\begin{array}{c}\text { Bacterial } \\
\text { isolate }\end{array}$ & $122 / 69$ & 103 & 0 & 47 & 4 \\
\hline Yusuf et al, 2014 20 & $\begin{array}{c}\text { Bacterial } \\
\text { isolate }\end{array}$ & $45 / 47$ & 41 & 0 & 47 \\
\hline
\end{tabular}

${ }^{\text {a }}$ carpa + /carpa-, carbapenemase producer / non carbapenemase producer

${ }^{\mathrm{b}} \mathrm{TP}$, true positive samples detected by CARBA NP test in comparison with PCR

${ }^{\mathrm{C}} \mathrm{FP}$, false positive samples detected by CARBA NP test in comparison with PCR

${ }^{\mathrm{d}} \mathrm{TN}$, true negative samples detected by CARBA NP test in comparison with PCR

${ }^{\mathrm{e}} \mathrm{FN}$, false negative samples detected by CARBA NP test in comparison with PCR

\section{Quality of Included Studies}

The included studies were free of a high level of bias, because of the inclusion and exclusion criteria. Though, the risk of bias related to patient selection was complicated to estimate. However, only $55 \%$ of the included studies reported that CARBA NP test results were interpreted without knowledge of the PCR results, a serious source of bias. The overall risk of bias and the concerns regarding applicability is presented in (Graph. 1) using the QUADAS-2 criteria. The concerns regarding applicability were generally low.

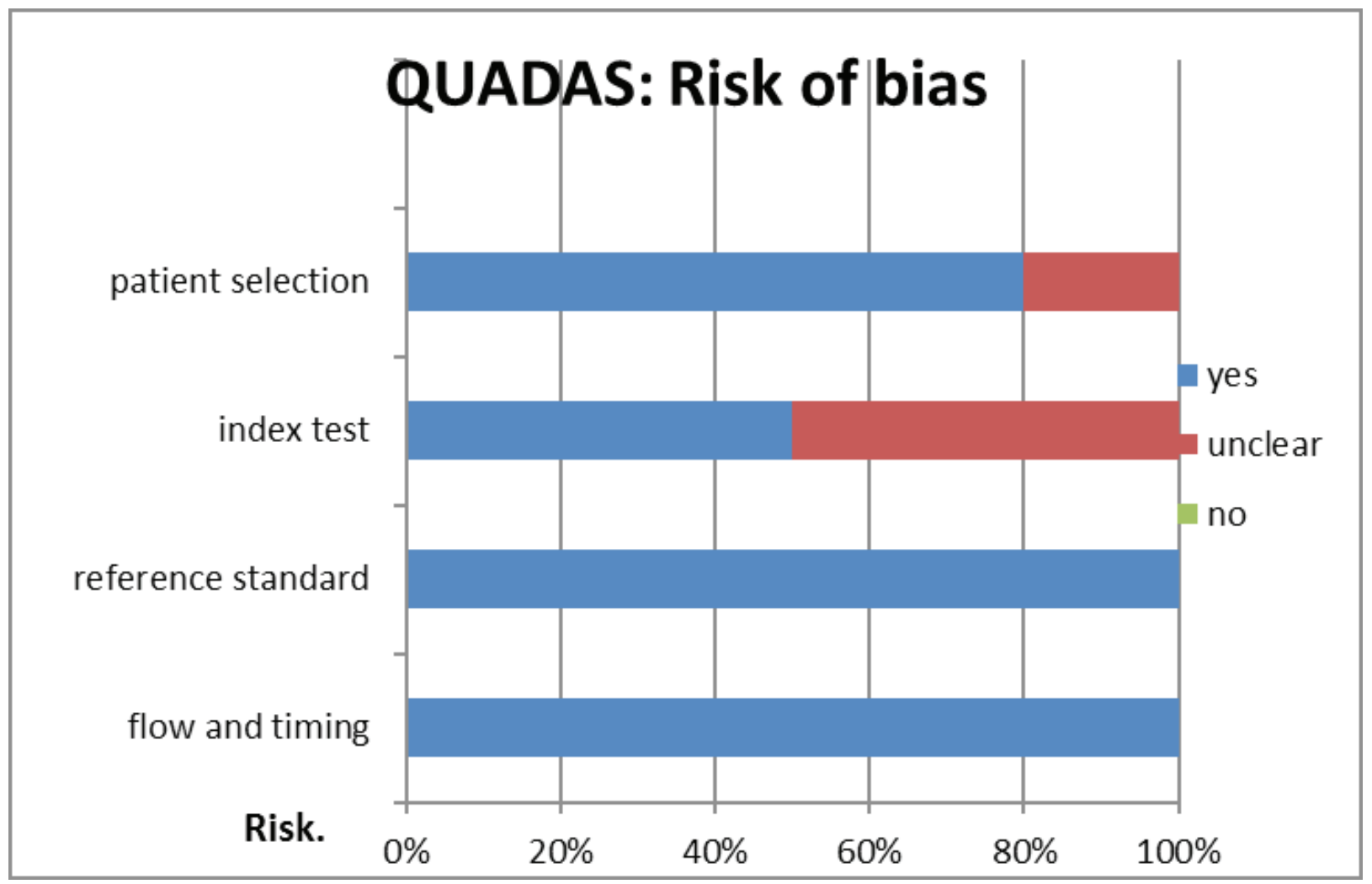




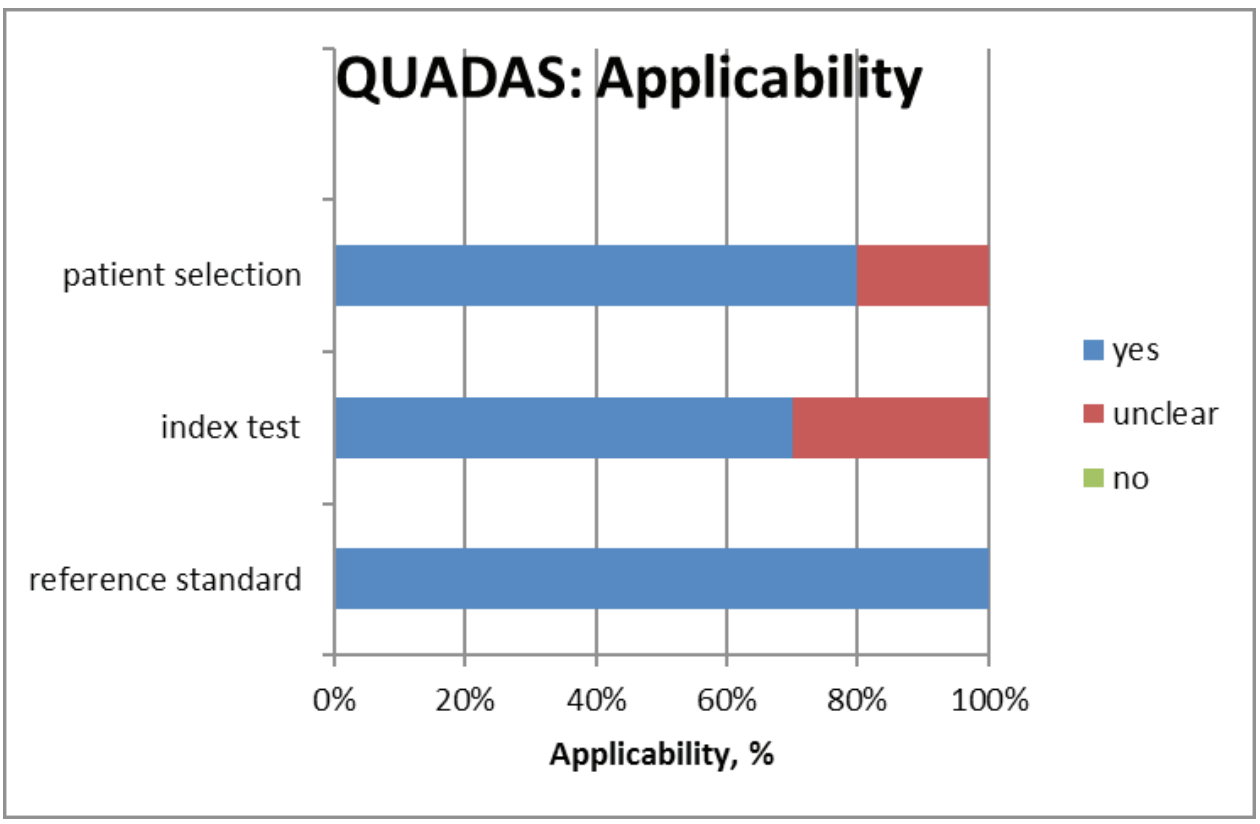

Graph. 1 Quality estimation of included studies using (QUADAS-2) criteria

Overall Accuracy of CARBA NP test for detection of Carbapenemase-Producing Enterobacteriaceae

(Graph. 2) shows forest plots of the sensitivities and specificities of the 18 CARBA NP test assays for the detection of Carbapenemase-Producing Enterobacteriaceae. The sensitivity and specificity ranged from 0.63 to 1.00 (mean, $0.96 ; 95 \% \mathrm{CI}, 0.92$ to
0.98 ) and from 0.71 to 1.00 (mean, $1.00 ; 95 \%$ CI, 0.97 to 1.00$)$, respectively. PLR was 33.1 ( $95 \% \mathrm{CI}, 24.3$ to 45.1), NLR was 0.06 (95\% CI, 0.05 to 0.07$)$, and DOR was $573.46(95 \% \mathrm{CI}, 397.4$ to 827.49$)$. The I-square tests for heterogeneity in the summary results suggested significant heterogeneity for sensitivity and specificity.
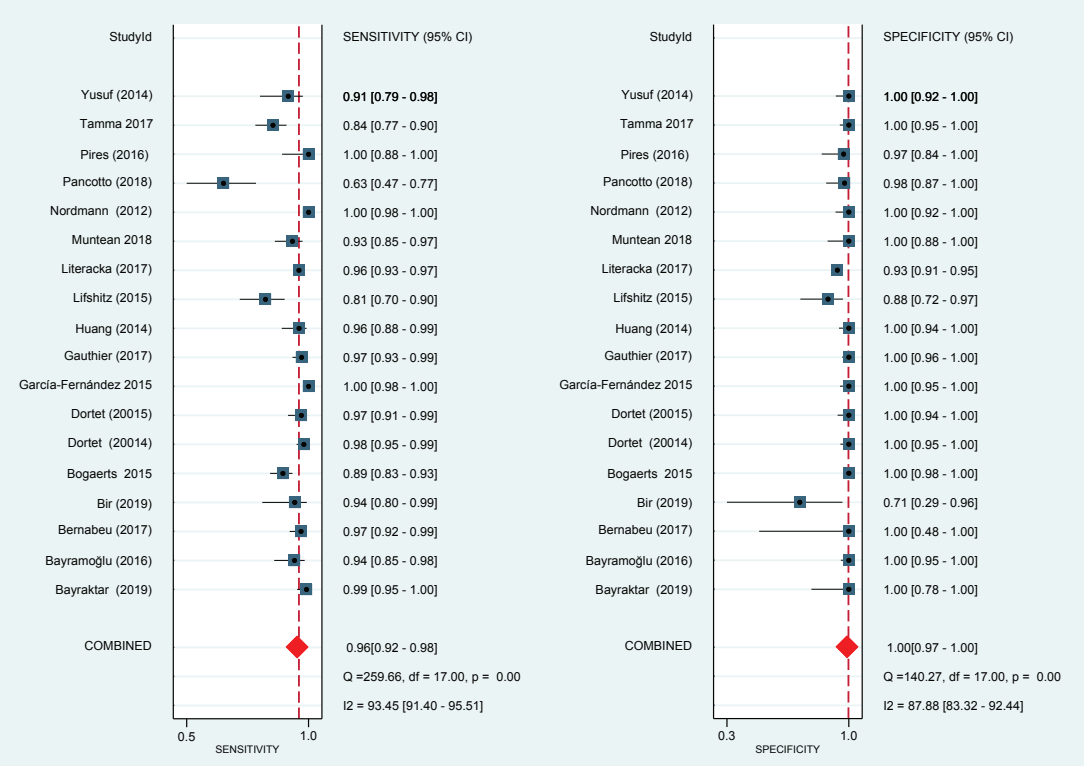

Graph. 2 Forest plot for the estimate of sensitivity and specificity of carba NP test for the rapid detection of Carbapenemase-Producing Enterobacteriaceae. Red diamond shape indicates the pooled sensitivity and specificity 
The SROC is considered as an international summary of test accuracy, it shows true-positive rates versus false-positive rates from individual studies. The SROC for CARBA NP test showed it was positioned at the upper left corner of the curve, and the area under the curve (AUC) was 1.00, which means that CARBA NP test has a high level of accuracy (Graph. 3).

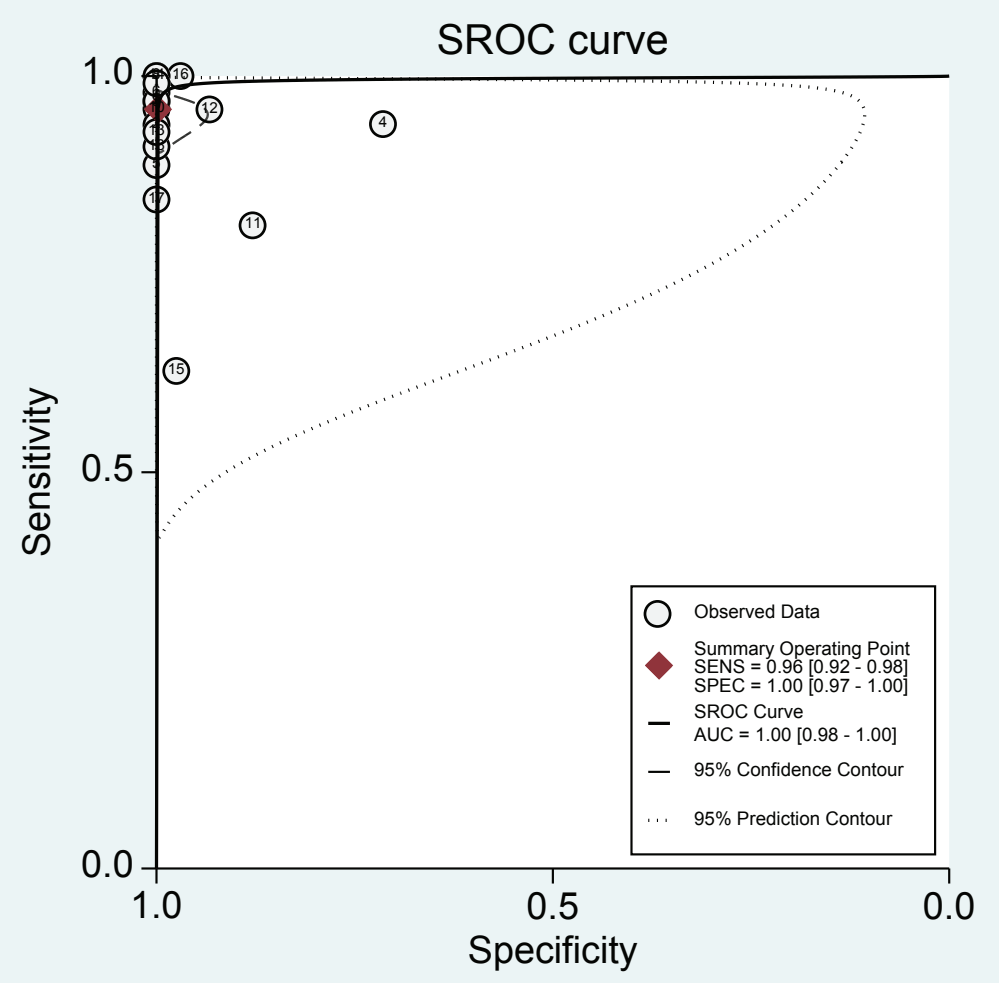

Graph. 3 Summary receiver operating characteristic (SROC) for CARBA NP test. Each hollow circle represents each study in the meta-analysis. The summary operating point is shown as a red diamond (with surrounding $95 \%$ confidence and prediction contours). AUC: area under the curve was 1.00 indicating a

high level of overall accuracy.

Investigation of heterogeneity: Meta-regression has been used to explore between-study heterogeneity. There were no statistically significant differences in sensitivity and specificity of CARBA NP test between studies with or without a clear definition of CARBA NP test, and between studies according to the type of specimens, and the design of the study ( retrospective, prospective) (Table 2).

Table 2. Meta-regression of the effects of methodological issues and study design on diagnostic accuracy of CARBA NP test in 18 assays

\begin{tabular}{|ccccc|}
\hline Covariate & Category (studies) & $\begin{array}{c}\text { Pooled } \\
\text { sensitivity } \\
(\mathbf{9 5 \%} \text { CI) }\end{array}$ & $\begin{array}{c}\text { Pooled specificity } \\
\text { (95\% CI) }\end{array}$ & $\begin{array}{c}\text { P value for the } \\
\text { joint model }\end{array}$ \\
\hline \multirow{2}{*}{ Sample ( bacterial isolate) } & Yes (17) & $0.96(0.93-0.98)$ & $100(0.98-100)$ & 0.67 \\
& No (1) & $0.98(0.93-100)$ & $100(100-100)$ & \\
\hline
\end{tabular}


Cont... Table 2. Meta-regression of the effects of methodological issues and study design on diagnostic accuracy of

\begin{tabular}{|ccccc|}
\hline \multirow{2}{*}{ Study design ( prospective) } & Yes (13) & $0.94(0.90-0.98)$ & $100(0.99-100)$ & 0.1 \\
& No (5) & $0.99(0.97-100)$ & $100(100-100)$ & 0.23 \\
\hline \multirow{2}{*}{ Definition of CARBA NP test } & Yes (16) & $0.95(0.90-0.98)$ & $100(0.99-100)$ & $100(100-100)$ \\
& No (2) & $0.99(0.97-100)$ & \\
\hline
\end{tabular}

\section{Discussion}

Carbapenem-Resistant Enterobacteriaceae (CRE) can cause serious consequences in the health care setting, so the rapid and precise identification of carbapenemase producers is very important to improve public health procedures by control infection contact and avoiding unnecessary antibacterial use ${ }^{7,33}$.

Although molecular methods are considered the gold standard for CRE detection, they less commonly used because of their high cost and the need for special laboratory facilities ${ }^{34-36}$, therefore, many phenotypic methods which are fast, accurate, and cheap have been suggested, the most common one is Carba NP test ${ }^{7,37-39}$.

The present meta-analysis showed that the sensitivity and specificity of Carba NP test were 0.96 and 1.00, respectively, the AUC was 1.00, and the mean DOR was 573.46 indicating a high level of overall accuracy. We also noted that one study [9] showed low sensitivity (0.63), and one study ${ }^{10}$ demonstrated a low specificity (0.71) when they used Carba NP test for the rapid detection of carbapenemase production.

In the present meta-analysis, the PLR and NLR values were 33.1 and 0.06 , respectively, indicating that if the Carba NP test result is positive, the isolate of Enterobacteriaceae is about 33 times more likely of being carbapenemase producer, whereas if the Carba NP test result is negative, the probability that the isolate in the sample is carbapenemase producer is 0.06 , which is low enough to rule out carbapenemase producer. These data suggest that the physicians can diagnose CPE with confidence on the basis of the Carba NP test result.

Meta-analysis aims to interpret the heterogeneity between studies as it is a very important impact factor
40. There was significant heterogeneity for sensitivity and specificity among the studies, but there were no statistically significant differences in sensitivity and specificity of CARBA NP test between studies with or without a clear definition of CARBA NP test, and according to the type of specimens, and the design of the study (retrospective, prospective).

However, the blinded test which is an important factor of avoiding bias was missing in $45 \%$ of included studies, so it is a possible reason for heterogeneity. Principally; the results of CARBA NP test are interpreted by the naked eye, so the reading of these results are very subjective and different according to the observer, especially when the change in the color is weak ${ }^{41-43}$.

On the other hand, the difference in the geographic and genetic distribution of carbapenemases might be another factor explains the heterogeneity in this study. The presence of OXA-48-like carbapenemases remarkably reduce the sensitivity of Carba NP test, because of its low hydrolysis activity ${ }^{12,39}$. This class of carbapenemase is rare in the USA. According to CDC data, OXA-48-like carbapenemases were detected just in 43 patients during a study that was carried in August 2015 included 19 states [44]. On the contrary OXA48-like carbapenemases have high spread in Europe, especially in Mediterranean countries ${ }^{1}$. Turkey detected OXA-48-like producers in $92 \%$ of $\mathrm{CPE}^{45}$.

The present study has many strengths aspects. First of all, a standard strategy was applied for implementing the systematic review 46, 47. Furthermore, different reviewers independently perform the same stage of the systematic review, including study selection, data extraction, and the assessment of study quality to reduce 
the risk of subjectivity as possible. Finally, precise methods were carried out for meta-analysis.

This systematic review was limited by insufficient data about the impact of CARBA NP test on the clinical outcomes, in addition to the lack of data on costeffectiveness and feasibility in routine management.

Carba NP test needs some equipment and freshly prepared reagents daily, making its use somewhat troubling, so some companies proposed a commercial version that is ready to- use (the Rapidec Carba NP) to be easier. Both version's results are interpreted in less than 2 hours by the naked eye (color change). Many studies evaluated the accuracy of the commercial version, the sensitivity and the specificity were varying between 90 $100 \%$ and $84-100 \%$ respectively $37,48-50$.

Carba NP test is cheap, each test costs ( $1 \$$ to $4 \$)$, whereas the commercial versions are more expensive ( $2.50 \$$ to $15.00 \$)$ per test according to the quality of the material. Although this cost is close to the cost of Antibiotic susceptibility testing (AST), but the AST needs 24 hours which is very longer than Carba NP test (less than 2 hours). Anyway, the molecular methods that are the gold standard for carbapenemase producers are more expensive about $40 \$$.

Furthermore, additional studies are required to determine the accuracy of Carba NP test when it is applied directly to clinical specimens. One study evaluated Carba NP test for rapid detection of carbapenemase-producing Enterobacteriaceae from blood cultures ${ }^{22}$, the sensitivity and specificity were $97.9 \%$ and $100 \%$, respectively, so by using Carba NP test, the time for identification of CPE that cause bacteremia can be shorter (3-5 h instead of 2448h). Sputum and cerebral spinal fluid samples should be included in more studies to assist in two situations: (i) detection of CPE in endemic countries (ii) in an outbreak situation when the $\mathrm{CPE}$ are strongly suspected.

\section{Conclusion}

The present systematic review and meta-analysis concluded that Carba NP test has a high level of accuracy for the detection of CPE, with caution in countries where low hydrolytic activity carbapenemases spread largely.
However, if further studies indicate that Carba NP test can detect CPE precisely when applied directly to clinical samples, it will be a very useful test as a rapid, cheap, and accurate screening test, especially in areas with high rates of carbapenemase-producing Enterobacteriaceae.

Acknowledgements: Not applicable.

Funding: This research did not receive any specific grant from funding agencies in the public, commercial, or not-for-profit sectors.

Conflicts of Interest/Competing Interests: On behalf of all authors, the corresponding author states that there is no conflict of interest

Ethical Clearance: None

\section{References}

1. Nordmann P, Naas T, Poirel L. Global spread of Carbapenemase-producing Enterobacteriaceae. Emerg Infect Dis 2011; 17(10):1791-1798.

2. Ramos-Castañeda JA, Ruano-Ravina A, Barbosa-Lorenzo R, et al. Mortality due to KPC carbapenemase-producing Klebsiella pneumoniae infections: Systematic review and meta-analysis: Mortality due to KPC Klebsiella pneumoniae infections. J Infect 2018; 76(5):438-448.

3. United States Centers for Disease Control and Prevention. Antibiotic resistance threats in the United State 2013. CDC. https://www.cdc. gov/drugresistance/Threat-Report-2013/pdf/arThreats-2013-508.pdf (Accessed 2013)

4. United States Centers for Disease Control and Prevention. Antibiotic resistance threats in the United State 2019. Available at: https://www.cdc. gov/drugresistance/pdf/threats-report/2019-arthreats-report-508.pdf (Accessed 2019)

5. Queenan AM, Bush K. (2007) Carbapenemases: the versatile beta-lactamases. Clin Microbiol Rev 2007; 20(3):440-458.

6. Dortet L, Poirel L, Nordmann P. Worldwide dissemination of the NDM-type carbapenemases in Gram-negative bacteria. Biomed Res Int 2014; 2014:249856.

7. Nordmann P, Poirel L. The difficult-to-control 
spread of carbapenemase producers among Enterobacteriaceae worldwide. Clin Microbiol Infect 2014; 20(9):821-830.

8. Nordmann P, Poirel L, Dortet L. Rapid detection of carbapenemase-producing Enterobacteriaceae. Emerg Infect Dis 2012; 18(9):1503-1507.

9. Pancotto LR, Nodari CS, Rozales FP, et al. Performance of rapid tests for carbapenemase detection among Brazilian Enterobacteriaceae isolates. Braz J Microbiol 2018; 49(4):914-918.

10. Bir R, Mohapatra S, Kumar A, et al. Comparative evaluation of in-house Carba NP test with other phenotypic tests for rapid detection of carbapenemresistant Enterobacteriaceae. J Clin Lab Anal 2019; 33(1):e22652.

11. Dortet L, Agathine A, Naas T, Cuzon G, Poirel L, Nordmann P. Evaluation of the RAPIDEC ${ }^{\circledR}$ CARBA NP, the Rapid CARB Screen ${ }^{\circledR}$ and the Carba NP test for biochemical detection of carbapenemase-producing Enterobacteriaceae. J Antimicrob Chemother 2015; 70(11):3014-3022.

12. Srisrattakarn A, Lulitanond A, Wilailuckana C, Charoensri N, Daduang J, Chanawong A. A novel GoldNano Carb test for rapid phenotypic detection of carbapenemases, particularly OXA type, in Enterobacteriaceae, Pseudomonas aeruginosa and Acinetobacter spp. J Antimicrob Chemother 2017; 72(9):2519-2527.

13. Simner PJ, Johnson JK, Brasso WB, et al. Multicenter Evaluation of the Modified Carbapenem Inactivation Method and the Carba NP for Detection of Carbapenemase-Producing Pseudomonas aeruginosa and Acinetobacter baumannii. J Clin Microbiol 2017; 56(1):e0136917.

14. Simner PJ, Opene BNA, Chambers KK, Naumann ME, Carroll KC, Tamma PD. Carbapenemase Detection among Carbapenem-Resistant GlucoseNonfermenting Gram-Negative Bacilli. J Clin Microbiol 2017; 55(9):2858-2864.

15. Dortet L, Poirel L, Errera C, Nordmann P. CarbAcineto NP test for rapid detection of carbapenemase-producing Acinetobacter spp. J Clin Microbiol 2014; 52(7):2359-2364.

16. Whiting PF, Rutjes AW, Westwood ME, et al. QUADAS-2: a revised tool for the quality assessment of diagnostic accuracy studies. Ann Intern Med 2011; 155(8):529-536.

17. Zamora, J., Abraira, V., Muriel, A. et al. MetaDiSc: a software for meta-analysis of test accuracy data. BMC Med Res Methodol 2006; 6, 31.

18. Moses LE, Shapiro D, Littenberg B. Combining independent studies of a diagnostic test into a summary ROC curve: data-analytic approaches and some additional considerations. Stat Med 1993; 12(14):1293-1316.

19. Huang TD, Berhin C, Bogaerts P, Glupczynski Y. Comparative evaluation of two chromogenic tests for rapid detection of carbapenemase in Enterobacteriaceae and in Pseudomonas aeruginosa isolates. J Clin Microbiol 2014; 52(8):3060-3063.

20. Yusuf E, Van Der Meeren S, Schallier A, Piérard D. Comparison of the Carba NP test with the Rapid CARB Screen Kit for the detection of carbapenemase-producing Enterobacteriaceae and Pseudomonas aeruginosa. Eur J Clin Microbiol Infect Dis 2014; 33(12):2237-2240.

21. Bogaerts $\mathrm{P}$, Yunus S, Massart M, Huang TD, Glupczynski Y. Evaluation of the BYG Carba Test, a New Electrochemical Assay for Rapid Laboratory Detection of CarbapenemaseProducing Enterobacteriaceae. J Clin Microbiol 2016; 54(2):349-358.

22. Dortet L, Bréchard L, Poirel L, Nordmann P. Rapid detection of carbapenemase-producing Enterobacteriaceae from blood cultures. Clin Microbiol Infect 2014; 20(4):340-344.

23. Gauthier L, Bonnin RA, Dortet L, Naas T. Retrospective and prospective evaluation of the Carbapenem inactivation method for the detection of carbapenemase-producing Enterobacteriaceae. PLoS One 2017; 12(2):e0170769. Published 2017 Feb 3.

24. Bernabeu S, Dortet L, Naas T. Evaluation of the $\beta$-CARBA ${ }^{\mathrm{TM}}$ test, a colorimetric test for the rapid detection of carbapenemase activity in Gramnegative bacilli. J Antimicrob Chemother 2017; 72(6):1646-1658.

25. Muntean MM, Muntean AA, Gauthier L, et al. Evaluation of the rapid carbapenem inactivation 
method (rCIM): a phenotypic screening test for carbapenemase-producing Enterobacteriaceae. J Antimicrob Chemother 2018; 73(4):900-908.

26. Lifshitz Z, Adler A, Carmeli Y. Comparative Study of a Novel Biochemical Assay, the Rapidec Carba NP Test, for Detecting Carbapenemase-Producing Enterobacteriaceae. J Clin Microbiol 2016; 54(2):453-456.

27. Literacka E, Herda M, Baraniak A, et al. Evaluation of the Carba NP test for carbapenemase detection in Enterobacteriaceae, Pseudomonas spp. and Acinetobacter spp., and its practical use in the routine work of a national reference laboratory for susceptibility testing. Eur J Clin Microbiol Infect Dis 2017; 36(11):2281-2287.

28. García-Fernández S, Morosini MI, Gijón D, et al. Detection of Carbapenemase Production in a Collection of Enterobacteriaceae with Characterized Resistance Mechanisms from Clinical and Environmental Origins by Use of Both Carba NP and Blue-Carba Tests. J Clin Microbiol 2016; 54(2):464-466.

29. Pires J, Tinguely R, Thomas B, Luzzaro F, Endimiani A. Comparison of the in-house made Carba-NP and Blue-Carba tests: Considerations for better detection of carbapenemase-producing Enterobacteriaceae. J Microbiol Methods 2016; 122:33-37.

30. Bayramoğlu G, Uluçam G, Gençoğlu Özgür Ç, Kılıç AO, Aydın F. Comparison of the modified Hodge test and the Carba NP test for detection of carbapenemases in Enterobacteriaceae isolates. Mikrobiyol Bul 2016; 50(1):1-10.

31. Bayraktar B, Barış A, Malkoçoğlu G, Erdemir D, Kina N. (2019) Comparison of Carba NP-Direct, Carbapenem Inactivation Method, and $\beta$-CARBA Tests for Detection of Carbapenemase Production in Enterobacteriaceae. Microb Drug Resist 2019; 25(1):97-102.

32. Tamma PD, Opene BN, Gluck A, Chambers KK, Carroll KC, Simner PJ. Comparison of 11 Phenotypic Assays for Accurate Detection of Carbapenemase-Producing Enterobacteriaceae. J Clin Microbiol 2017; 55(4):1046-1055.
33- Cantón R, Akóva M, Carmeli Y, et al. Rapid evolution and spread of carbapenemases among Enterobacteriaceae in Europe. Clin Microbiol Infect 2012; 18(5):413-431.

34- Martino MD, Koga PC, Pasternak J, et al. Evaluation of a new rapid test for carbapenemase detection in carbapenem resistant Enterobacteriaceae. J Microbiol Methods 2015; 115:20-21.

35- Hemarajata P, Yang S, Hindler JA, Humphries RM. Development of a novel real-time PCR assay with high-resolution melt analysis to detect and differentiate OXA-48-Like $\beta$-lactamases in carbapenem-resistant Enterobacteriaceae. Antimicrob Agents Chemother 2015; 59(9):55745580.

36- Hrabák J, Chudáčková E, Papagiannitsis CC. Detection of carbapenemases in Enterobacteriaceae: a challenge for diagnostic microbiological laboratories. Clin Microbiol Infect 2014; 20(9):839853.

37- Noël A, Huang TD, Berhin C, et al. Comparative Evaluation of Four Phenotypic Tests for Detection of Carbapenemase-Producing Gram-Negative Bacteria. J Clin Microbiol 2017; 55(2):510-518.

38- Bogaerts, P., Oueslati, S., Meunier, D. et al. Multicentre evaluation of the BYG Carba v2.0 test, a simplified electrochemical assay for the rapid laboratory detection of carbapenemase-producing Enterobacteriaceae. Sci Rep 2017; 7, 9937.

39- HuberCA, SidjabatHE, ZowawiHM, etal. Detection of carbapenemase activity in Enterobacteriaceae using LC-MS/MS in comparison with the neorapid CARB kit using direct visual assessment and colorimetry. J Microbiol Methods 2016; 131:6872.

40- Petitti DB. Approaches to heterogeneity in metaanalysis. Stat Med 2001; 20(23):3625-3633.

41- Tijet N, Boyd D, Patel SN, Mulvey MR, Melano RG. Evaluation of the Carba NP test for rapid detection of carbapenemase-producing Enterobacteriaceae and Pseudomonas aeruginosa. Antimicrob Agents Chemother 2013; 57: 4578 \pm 4580 .

42- Yamada K, Kashiwa M, Arai K, Nagano N, Saito R. Comparison of the Modified-Hodge test, Carba NP test, and carbapenem inactivation method as 
screening methods for carbapenemase-producing Enterobacteriaceae. J Microbiol Methods 2016; 128: $48 \pm 51$.

43- Tijet N, Patel SN, Melano RG. Detection of carbapenemase activity in Enterobacteriaceae: comparison of the carbapenem inactivation method versus the Carba NP test. J Antimicrob Chemother 2016; $71: 274 \pm 276$.

44- Lyman M, Walters M, Lonsway D, Rasheed K, Limbago B, Kallen A. Notes from the Field: Carbapenem-resistant Enterobacteriaceae Producing OXA-48-like Carbapenemases--United States, 2010-2015. MMWR Morb Mortal Wkly Rep. 2015 Dec 4;64(47):1315-6.

45- Baran I, Aksu N. Phenotypic and genotypic characteristics of carbapenem-resistant Enterobacteriaceae in a tertiary-level reference hospital in Turkey. Ann Clin Microbiol Antimicrob 2016; 15:20.

46- Pai M, McCulloch M, Enanoria W, Colford JM Jr. Systematic reviews of diagnostic test evaluations: What's behind the scenes?. ACP J Club 2004;
141(1):A11-A13.

47- Deeks JJ. Systematic reviews in health care: Systematic reviews of evaluations of diagnostic and screening tests. BMJ 2001; 323(7305):157-162.

48- Kabir MH, Meunier D, Hopkins KL, Giske CG, Woodford N. A two-centre evaluation of RAPIDEC $\AA$ CARBA NP for carbapenemase detection in Enterobacteriaceae, Pseudomonas aeruginosa and Acinetobacter spp. J Antimicrob Chemother 2016; 71(5):1213-1216.

49- Elawady B, Ghobashy M, Balbaa A. Rapidec Carba NP for Detection of Carbapenemase-Producing Enterobacteriaceae in Clinical Isolates: A CrossSectional Study. Surg Infect (Larchmt) 2019; 20(8):672-676.

50- Hombach M, von Gunten B, Castelberg C, Bloemberg GV. Evaluation of the Rapidec Carba NP Test for Detection of Carbapenemases in Enterobacteriaceae. J Clin Microbiol 2015; 53(12):3828-3833. 